\title{
Aproximación sociológica al significado de los términos: economía popular, economía social y economía solidaria en México
}

\author{
Juan José Rojas Herrera \\ Universidad Autónoma Chapingo, México
}

Resumen

A pesar de la globalización de la economía y los incesantes intentos por subordinar todas las formas de producción a la lógica de la acumulación capitalista, la resistencia de los trabajadores persiste mediante la implementación de diversos modelos de gestión social del trabajo, entre los que destacan los puestos en marcha por los actores de la economía popular, la economía social y la economía solidaria. Precisar la identidad organizacional de estas tres formas de trabajo, para el caso específico de México, constituye el propósito principal del presente artículo, habiéndose identificado que, por su naturaleza, el sistema de trabajo que corresponde a cada una de ellas es de tipo autónomo, asociativo-autogestionario y asociativoautogestionario-solidario, respectivamente.

\section{Palabras clave:}

Trabajo; economía popular; economía social; economía solidaria; autogestión

Códigos JEL: P13, B55, J47, A14

\section{SOCIOLOGICAL APPROACHTO THE MEANING OF THE TERMS: POPULAR ECONOMY, SOCIAL ECONOMY AND SOLIDARITY ECONOMY IN MEXICO}

\section{Abstract}

Despite the globalization of the economy and the incessant attempts to subordinate all forms of production to the logic of capitalist accumulation, the resistance of workers persists through the implementation of various models of social work management, among which the posts launched by the actors of the popular economy, the social economy and the solidarity economy. Specify the organizational identity of these three forms of work, for the specific case of Mexico, is the main purpose of this article, having identified that, by its nature, the work system that corresponds to each of them is of autonomous type, associativeself-management and associative-self-management-solidarity, respectively.

\section{Keywords}

Work; popular economy; social economy; solidarity economy; self-management

JEL codes: P13, B55, J47, A14

Fecha de recepción del original: 14 de junio de 2018; versión definitiva: 18 de diciembre de 2019.

Juan José Rojas Herrera, Universidad Autónoma Chapingo, Departamento de Sociología Rural. Km. 38.5 de la carretera federal: MéxicoTexcoco. Municipio de Texcoco. CP. 56230.

Tel.: +52 5959521625 . Ext. 6528; E-mail: rojashjj@gmail.com.

ORCID ID: 0000-0003-4842-9685 


\title{
Aproximación sociológica al significado de los términos: economía popular, economía social y economía solidaria en México
}

\author{
Juan José Rojas Herrera \\ Universidad Autónoma Chapingo, México
}

I. Introducción

Una de las características más notorias de la economía globalizada de nuestros días es la insuficiencia crónica en la generación de empleo, lo que ha derivado en una auténtica crisis del sistema de trabajo asalariado. Dicha crisis se manifiesta en el hecho de que para cada vez más amplios segmentos de la población ya no es posible vivir del trabajo subordinado a un patrón. Esto se debe, en buena medida, a los efectos de la revolución tecnológica, que demanda poca fuerza de trabajo con alto nivel educativo, así como a la severa reducción del papel del Estado como productor de bienes públicos y como empleador. De esta manera, se produce una separación entre quienes tienen las habilidades para entrar y permanecer en el sistema productivo y quienes no las tienen. Los primeros gozarán de oportunidades si aceptan las condiciones de la flexibilización laboral, en tanto que los segundos serán excluidos del mercado laboral formal, convirtiéndose en destinatarios de las políticas de asistencia social y candidatos a engrosar las filas de la economía informal.

La crisis del sistema de trabajo asalariado se ve igualmente agravada por el predominio del llamado fenómeno de financiarización del capital y que no es otra cosa que la hegemonía del capital financiero sobre el capital productivo. Bajo estas condiciones, la creación de riqueza pasa cada vez menos por el proceso productivo, lo que se traduce en menores posibilidades de generación de empleos.

Finalmente, vale la pena considerar también la existencia de una correlación de fuerzas desfavorable al mundo del trabajo, lo que permite imponer políticas laborales que reducen el empleo y deprimen las condiciones de trabajo y los salarios. Se produce así un grave estancamiento del sindicalismo, la agudización de la competencia profesional y el reforzamiento del individualismo y del egoísmo como estrategias de sobrevivencia individual.

Dada esta realidad, la búsqueda incesante de alternativas de trabajo e ingresos no asalariados, así como de formas diferentes de organizar el trabajo y, por ende, la vida económica, se pone a la orden del día. Esto explica que en todas partes se viva una explosión asociativa, una gran innovación y un activismo que promueve todo tipo de figuras asociativas y los más diversos mo- delos alternativos de gestión económica para hacer frente a la lógica dominante del capital. En el caso de México, los modelos con mayor tradición histórica y que actualmente cuentan con una presencia macroeconómica y social plenamente reconocida son los identificados como economía popular (EP), economía social (ES) y economía solidaria (ESD).

En este contexto, el objetivo general del presente artículo consiste en avanzar en la delimitación teórica y conceptual de la distinta lógica de funcionamiento de los modelos de gestión propios de cada una de las formas de organización social del trabajo que subyacen a la EP, la ES y la ESD. Una tarea de enorme importancia, no solamente desde el punto de vista de la indispensable claridad teórica y epistemológica que se requiere para valorar con justeza el potencial innovador y transformador de cada una de estas formas de organización social, sino también en el orden práctico para el diseño y elaboración de una estrategia de acción colectiva que permita ejercer una defensa más efectiva de los intereses inmediatos e históricos de los trabajadores mexicanos.

En consecuencia, el trabajo y sus formas de gestión colectiva es la categoría de análisis central, ya que esencialmente lo que distingue a la EP, la ES y la ESD es la relación social del trabajo utilizada. Reforzando esta misma idea, Caracciolo y Foti (2003: 19), han destacado que todas estas formas de organización social y económica están integradas por una heterogeneidad de actores, la mayoría excluidos de relaciones laborales formales, "para quienes su fuerza y su valor económico radica en su propio trabajo". Es decir, tienen como fuente principal de creación de valor al trabajo y lo hacen con criterios sociales, a través de relaciones solidarias, igualitarias y equitativas de producción. Más aún, de acuerdo con Fernández (2013: 107), debe tomarse en cuenta que estas asociaciones colectivas "preconizan el trabajo como un medio de liberación humana dentro de un proceso de democratización económica, y pretenden crear así una alternativa a la dimensión alienante y asalariada de las relaciones de trabajo capitalista".

Por otra parte, en lo que hace al procedimiento metodológico empleado, consideramos indispensable señalar que partimos de tres modelos de organización del trabajo que han sido empíricamente validados a lo largo de las últimas tres décadas en diferentes contextos regionales. Nuestra reflexión teórica, mediante el uso de la abstracción científica y el método inductivo, ha procurado ubicar las regularidades que distinguen a dichas formas de organización, tratando primeramente de identificar las variables 
o factores que determinan la dinámica interna de los modelos en cuestión y, posteriormente, la forma en que tales variables se relacionan entre sí dentro de un sistema cerrado. A manera de colofón, la deliberación teórica se ha completado con un análisis comparativo global entre modelos.

En el orden expositivo, empezaremos por establecer los criterios que nos servirán para llevar a cabo la identificación y delimitación de los modelos de gestión señalados, por lo que, una vez armados con dicho instrumental teórico, procederemos a describir los componentes específicos de cada uno. Posteriormente, se realizará un análisis comparativo mediante el que intentaremos ubicar las semejanzas y diferencias existentes entre éstos y, finalmente, presentaremos las conclusiones generales del estudio.

Antes de entrar en materia, estimamos importante hacer tres aclaraciones a fin de evitar malos entendidos. En primer lugar, reconocer que, en la práctica, no existe un emprendimiento químicamente puro o que reúna todos los atributos distintivos de cualquiera de los modelos de organización social antes indicados, lo cual significa que no son estáticos ni inmutables sino que poseen una dinámica cambiante e inestable que provoca su variabilidad en el tiempo, convirtiéndose en procesos inacabados o latentes de autoorganización y autogestión colectiva que pueden, incluso, dar lugar al surgimiento de entidades nuevas e hibridas de mayor complejidad, cuyo análisis en este trabajo, por razones de espacio, no es abordado. En segundo lugar, que es necesario reparar en las diferencias de orden espacial que tienen que ver con el hecho innegable de que los conceptos son definidos en forma diferente en cada país, de acuerdo con su propia experiencia concreta y su tradición histórica. Por tanto, lo que aquí se ofrece son un conjunto de definiciones que pretenden ser útiles y limitadas al caso mexicano, con un carácter flexible, abierto y de construcción inacabada y no como algo definitivo y conclusivo. En tercer lugar, que nuestro análisis se circunscribe a las unidades de base, dejando de lado a las estructuras de integración o de representación gremial destinadas a la defensa de los intereses de los organismos que agrupan y cuyo análisis pormenorizado requeriría de un instrumental teórico y metodológico distinto al que se empleará aquí.

II. Variables a considerar en la delimitación de las distintas formas de organización social del trabajo

La lógica de funcionamiento cotidiano de los modelos de gestión del trabajo aquí estudiados responde a la combinación de las siguientes variables: las características de los actores participantes y de los modelos organizativos empleados, el tipo de intereses que motivan sus acciones colectivas, los fines que persiguen, el tipo de relaciones o interacciones socioeconómicas y culturales establecidas hacia dentro y hacia afuera de los emprendimientos organizados, y las prácticas sociales y empresariales que desarrollan. El contenido específico de cada una de estas variables se aborda a continuación.
Características generales de los actores participantes y de los modelos organizativos empleados

En esta dimensión se trata básicamente de responder a las siguientes preguntas: ¿Quiénes son los actores principales en los distintos modelos de organización social estudiados: ¿personas físicas, morales o ambas? ¿Se trata de entidades con personalidad jurídica propia y estructura formal de organización o grupos informales no legalizados? ¿Qué tipo de unidades socioeconómicas forman prioritariamente: unidades domésticas, comunidades, organizaciones sociales o empresas? y ¿Qué características presentan dichos emprendimientos asociativos?

Como es sabido, un individuo o persona física es cualquier persona adulta, ya sea del sexo masculino o femenino, que cuenta con capacidad de aportar su trabajo físico o intelectual a fin de garantizar su reproducción social. La persona moral es el resultado de la unión de un grupo de individuos, quienes deciden organizarse a fin de potenciar el efecto de sus esfuerzos individuales, creando una unidad económica colectiva.

Para Coraggio (2003) la unidad doméstica está formada por un grupo de individuos, vinculados de manera sostenida, que son -de hecho o de derecho, por relaciones de parentesco, afinidad o contrato- solidaria y cotidianamente responsables de la obtención y satisfacción de las condiciones materiales necesarias para la reproducción inmediata de todos sus miembros. Una unidad doméstica puede abarcar uno o más hogares, entendiendo por "hogar" el grupo -generalmente "multifuncional"- que ejecuta diversas actividades económicas y que comparte y utiliza en común recursos o un presupuesto para la alimentación, la vivienda y otros gastos básicos.

Por su parte, una empresa es una unidad económica organizada para producir bienes y servicios destinados a la venta en distintos mercados. Con el término de comunidad entenderemos al conjunto de relaciones sociales que se establecen al interior de un agrupamiento social asentado en un mismo territorio, ya sea del medio rural o urbano, en el que se producen lazos interpersonales densos y fuertes y que eventualmente puede dar origen al desarrollo de una identidad común. Finalmente, la organización social es concebida como una red de relaciones establecidas entre las personas con un fin determinado, que solo se puede construir mediante la libre interacción entre sus integrantes en un ambiente de autonomía.

Ahora bien, entre las características generales que diferencian a los distintos emprendimientos asociativos, vale la pena distinguir, al menos, cuatro planos: uno de orden genealógico, otro de carácter legal, uno más de naturaleza ética y, el último, referido al grado de desarrollo organizacional alcanzado.

En cuanto a su génesis, lo que interesa básicamente es verificar la forma en que surgió la organización, ya sea desde arriba, como producto de una transferencia o imposición externa; como parte de un diseño o empeño enteramente propio, o bien como resultado de un proceso de incubación, asesoría y acompañamiento, a cargo de una organización empoderadora. Todo esto es importante si consideramos que la forma en que se constituyó el 
emprendimiento asociativo será determinante de su naturaleza, autenticidad y sostenibilidad a largo plazo.

En el orden jurídico, es importante definir si las unidades económicas cuentan con personalidad jurídica propia o no, si están reconocidas como interlocutores válidos en los distintos procesos de intermediación social y si son considerados como destinatarios naturales de las políticas públicas.

En el plano ético-filosófico, es fundamental establecer si disponen o no de un código de ética que inspire su acción social y se constituya en elemento integrador de la identidad común del colectivo organizado.

Finalmente, en el componente relativo a desarrollo organizacional, es necesario reparar en una serie de elementos que permiten precisar el grado de formalización y profesionalización de las estructuras organizativas, el nivel de división social del trabajo (DST) establecido y la capacidad de planeación, coordinación y evaluación de las actividades ejecutadas.

Tipo de intereses que motivan sus acciones colectivas

Si se aspira a identificar los intereses que motivan a los actores sociales en su interacción con otros, es imprescindible conocer, aunque sea de forma general, las necesidades que los alientan, es decir, la problemática que los genera y los empuja hacia la acción colectiva y organizada. En este marco de reflexión, sus intereses pueden dividirse entre los de carácter egoísta, individualista o particular y los de tipo general, colectivo o social. Pero, si este aspecto se aborda en términos de impacto e intencionalidad, ello obliga a deslindar quiénes son los que se benefician o perjudican de los resultados de las acciones colectivas realizadas por las diferentes organizaciones sociales.

Sobre la base anterior, los intereses pueden clasificarse en cinco tipos, a saber: exclusivistas o mutualistas, universalistas, altruistas, solidarios, y mixtos. En las organizaciones con intereses exclusivistas o mutualistas los únicos beneficiarios son las personas reconocidas como socios o miembros de la unidad económica de que se trate. En cambio, el interés adquiere una connotación universalista cuando los efectos de la acción colectiva de una organización benefician o perjudican no solamente a su base social de referencia sino a todos los miembros de la sociedad, de un gremio, de un grupo, de una comunidad, de un sector o de una clase o estrato social, independientemente de que formen parte o no de ésta. Por su parte, el interés altruista es aquel que define como únicos beneficiarios a terceras personas ajenas a la organización, ya sea que se trate de la comunidad en sentido general o grupos de población específicos, definidos como vulnerables e incapaces de valerse por sí mismos. El interés solidario, aunque también suele estar dirigido a los más débiles en la escala social, se diferencia del altruista en que no se restringe a atender una necesidad urgente, por razones de compasión o caridad, sino que trata de remediar una injusticia atacando las causas estructurales que la provocan. Finalmente, los intereses mixtos hacen alusión a una mezcla o combinación de intereses exclusivistas, universalistas, altruistas y solidarios, según se estipule en los documentos normativos de la organización de que se trate o resulten de su práctica concreta.

Un último aspecto a tomar en cuenta, es que si los intereses los ubicamos, según su consecución en el tiempo, éstos pueden ser de corto, mediano y largo plazo, es decir, inmediatos, mediatos e históricos.

Fines que persiguen

Los fines de las organizaciones adscritas a la EP, la ES y la ESD pueden ser de carácter económico o determinados por una aspiración social, ideológica, cultural, lúdica-recreativa o política. Unos u otros o ambos.

Los fines económicos pueden circunscribirse a la sobrevivencia o proponerse la elevación del nivel de vida. Normalmente en los primeros caben los esfuerzos individuales que se realizan en forma aislada o con participación del núcleo familiar, pero sin coordinación con agregados sociales más amplios, en tanto que los segundos, casi siempre, son resultado de la acción conjunta de varios individuos o familias en una forma de organización más amplia o extendida.

Los fines económicos, pueden alcanzarse con un enfoque restrictivo y utilitarista, propio de la racionalidad instrumental típicamente capitalista de fines-medios, condicionada por las influencias del mercado o responder a un fundamento ético que obliga a tomar en cuenta que los bienes y servicios que se produzcan sean socialmente necesarios, ponderando con responsabilidad la forma de obtenerlos, los costos sociales implícitos y sus externalidades. En esta segunda acepción, se trataría de producir pensando que los recursos disponibles son limitados y que hay que conservarlos para el disfrute de las futuras generaciones, actuando con una con lógica reproductiva; por lo tanto, no se intentaría solamente maximizar el valor suplementario a obtener, sino responder a diversos imperativos de naturaleza extraeconómica.

Generalmente cuando los fines económicos se pretenden alcanzar bajo la exclusiva lógica de maximizar el beneficio, éstos se convierten en lucrativos dejando abierta la posibilidad de explotar al hombre, destruir el medio ambiente, especular con la escasez, engañar y manipular a los consumidores y eliminar a los competidores. Por el contrario, participar en la actividad económica sin una finalidad lucrativa, implica poner en el centro el bienestar del hombre y la conservación de la naturaleza.

Por otro lado, la labor orientada a atender las aspiraciones o necesidades no económicas de los socios puede adquirir un carácter trascendente o intrascendente. La diferencia esencial entre uno y otro depende de la ponderación que se haga sobre las posibilidades reales de alcanzar o no la plena satisfacción de dichas aspiraciones en los marcos del contexto económico, político, social y cultural vigente. Las organizaciones sociales que pretenden alcanzar fines trascendentes estiman que el contexto general resulta incompatible a la total realización de tales aspiraciones y que, por tanto, se requiere modificar sustancialmente dicho contexto para alcanzar los fines deseados, mientras que las 
agrupaciones que desarrollan una labor no trascendente, consideran que el contexto general prevaleciente aún posibilita la satisfacción de las aspiraciones sociales, políticas y culturales por ellas enarboladas.

Tipo de relaciones o interacciones socioeconómicas y culturales establecidas hacia dentro y hacia fuera

En su devenir histórico, las distintas formas de organización del trabajo enfrentan diversas tensiones que están vinculadas con el carácter de las relaciones sociales dominantes en su vida interna y con su entorno, lo que se refleja en dicotomías, tales como: predominio del interés particular o del interés general, prevalencia de la rentabilidad o de la reciprocidad ${ }^{1}$ y autonomía o dependencia respecto al Estado y demás grupos externos de poder. La solución de tales contradicciones no suele alcanzarse en forma total y absoluta, ni mucho menos, por la vía de la eliminación, real o por decreto, del factor que genera la oposición, sino mediante la búsqueda del equilibrio, que se logra a través de la experimentación y el movimiento de los contrarios.

De esta suerte, para satisfacer sus intereses y lograr sus fines, los integrantes de los diferentes emprendimientos sociales invierten tiempo y energía en desarrollar un conjunto de interacciones socioeconómicas y culturales, que van a dar cuenta de la intensidad y calidad de su vida asociativa, la que, a su vez, depende del grado de confianza y reciprocidad que hayan cultivado, así como del tipo de lealtades o mística que los inspire. La fortaleza interna de la organización tiene que ver también con el grado de satisfacción de las expectativas y objetivos de los socios que pueden llegar a ser muy diversos. Por ejemplo, más allá del interés general por garantizar la sobrevivencia o elevar el nivel de vida, las mujeres pueden poner un especial énfasis en lograr la equidad de género y los jóvenes en ver reflejadas sus aspiraciones intergeneracionales. En cualquier caso, lo importante a rescatar es que, sin duda, la atención que se ofrezca a los aspectos antes indicados será determinante del ambiente de trabajo que se pueda crear. En definitiva, la autenticidad y originalidad de la vida asociativa de una unidad económica con vocación social será directamente proporcional a la calidad de las relaciones sociales establecidas entre sus integrantes.

En relación con su entorno inmediato, las asociaciones colectivas, necesitan establecer diferente tipo de relaciones con distintos grupos de interés, ya sean de carácter público o privado. Esto implica detenerse a analizar el grado de autonomía e independencia de la organización social, el cual dependerá de que efectivamente se haya configurado y pueda en consecuencia

\footnotetext{
${ }^{1}$ La reciprocidad puede entenderse como un eje articulador de voluntades individuales que se basa en vivir tomando en cuenta la existencia de los demás, así como sus necesidades e intereses. Lo que en última instancia se pretende lograr a través de la reciprocidad es establecer y fortalecer lazos de integración y compromiso duradero entre las personas.
}

conducirse, en sus vínculos con los demás, como un actor social con intereses y demandas propias ${ }^{2}$.

Desde la perspectiva estrictamente empresarial, es imperativo precisar si las relaciones con el exterior están alineadas o no y en qué grado con la llamada: responsabilidad social empresarial (RSE), entendida como la respuesta de las unidades económicas a las expectativas de los sectores y agentes con los que interactúa en su zona de influencia y con el medio ambiente. Por consiguiente, la RSE engloba todas las relaciones contractuales, implícitas o explícitas que la empresa tiene con aquellos colectivos con los que se relaciona, así como con la sociedad en general, tratando de maximizar el beneficio de todas las partes implicadas.

En resumen, una empresa puede estimarse como socialmente responsable cuando sus productos y servicios contribuyen al bienestar de la sociedad, sus actividades son respetuosas del medio ambiente, sus aportaciones al fisco son proporcionales a la riqueza generada, proporciona servicios educativos a sus socios, son respetados los derechos de los empleados y se fomenta el apoyo a los segmentos más desfavorecidos de las comunidades.

Prácticas sociales y empresariales

Un primer nivel de diferenciación de las prácticas de las organizaciones sociales nos llevaría a distinguirlas entre aquellas que están circunscritas al ámbito económico y las que pretenden abarcar los diferentes aspectos de la vida de sus asociados. En el primer caso, la organización se constriñe a actuar como una empresa eficiente y competitiva con capacidad de elevar el nivel de vida de sus agremiados, pero sin preocuparse por la problemática que les afecte en su calidad de ciudadanos o de consumidores. En cambio, cuando la organización social se compromete a atender las diferentes necesidades de sus integrantes, tiene que desarrollar otro tipo de actividades extraeconómicas, entre las que sobresalen las de tipo educativo, político y cultural.

Dentro del ámbito de las actividades económicas, éstas pueden dividirse en sistémicas o antisistémicas. Las sistémicas son todas aquellas prácticas típicas del mercado y de la acumulación capitalista y que, por tanto, no se apartan de la lógica reproductiva del capital. En sentido opuesto, las prácticas económicas antisistémicas responden a una racionalidad totalmente distinta a la del capital, ubicándose fuera de la órbita acumulativa del capitalismo.

En cuanto a las prácticas socioculturales, es importante tomar en cuenta que éstas se definen con respecto al sistema cultural e institucional establecido, pudiendo clasificarse en alineadas o no alineadas a dicho sistema. En caso de que tales prácticas se ubiquen como parte de las no alineadas, caerían dentro del campo mejor conocido como contracultural. Bajo este supuesto, la

\footnotetext{
2 De acuerdo con Alain Touraine (1987), un actor social es un sujeto colectivo estructurado e integrado en torno a una identidad o razón de vida común, que dispone de un determinado número de recursos que le permiten actuar en el seno de una sociedad con vistas a defender los intereses de los miembros que lo componen, a fin de dar respuesta a las necesidades identificadas por éstos como prioritarias.
} 
organización social funcionaría como un centro productor y reproductor de una cultura democrática y humanista enfocada en la formación cívica de sus agremiados como ciudadanos responsables y, eventualmente, como como animadores o líderes de sus comunidades.

En el campo de la política y en razón de la posición que asuman frente a la dominación del capital y sus agentes políticos, las prácticas sociales y empresariales de los emprendimientos asociativos, pueden clasificarse, de acuerdo con su distinto grado de radicalismo, en prácticas colectivas de adaptación, de resistencia, o de emancipación. Finalmente, como parte de las estrategias implementadas para su auto desarrollo y acumulación de fuerzas, éstas tienden a decantarse en torno al seguimiento de una vía empresarial, una vía comunitaria o una combinación de ambas.

Una vez establecido el marco teórico y conceptual desde el que se puede intentar una aproximación al análisis de la dinámica de las formas de organización social del trabajo implícitas en la EP, la ES y la ESD, veamos a continuación, de manera específica, lo que distingue a cada uno de estos modelos, añadiendo a los cinco elementos antes señalados, algunos datos que permitan dimensionar su presencia económica y social en el México contemporáneo, así como una definición operativa y flexible, para cada uno de ellos.

III. Análisis particular de los modelos de gestión social del trabajo

La Economía Popular

Hoy en día lo"popular", en el imaginario colectivo, está asociado con los bienes culturales y las costumbres de los grupos marginados de la sociedad mexicana, que constituyen la inmensa mayoría de la población del país. Su uso cotidiano y la capacidad de suscitar actos que derivan en determinadas representaciones es lo que da origen y razón de ser a la identidad colectiva de lo popular. Por ello, el concepto de EP, como señala Cadena (2005: 32), subraya "la naturaleza de sus principales actores, miembros de los sectores populares que han quedado en el desempleo y el subempleo", a raíz de la imposición del modelo neoliberal que produjo una enorme exclusión de población de los procesos productivos formales y que, a partir de entonces, empezó a presentar elevados niveles de vulnerabilidad.

En este contexto, las manifestaciones de lo que podemos identificar como EP, son protagonizadas por actores individuales o colectivos de escasos recursos económicos, asentados en el medio urbano o rural y que a menudo, surgen de manera espontánea, ante la necesidad de satisfacer necesidades vitales como la alimentación, la vivienda, el empleo, la salud o la seguridad social. No obstante, en un intento de ordenamiento, dentro de la EP es posible observar la existencia de diversos subgrupos, a saber: a) Emprendimientos unipersonales sostenidos por personas físicas, tales como: profesionistas libres o trabajadores autónomos, comerciantes minoristas, vendedores ambulantes, artesanos, tra- bajadoras domésticas, personas dedicadas a la economía del cuidado, etc.; b) Unidades domésticas como la agricultura familiar de autoconsumo, el taller artesanal, el changarro urbano, etc.); c) Comunidades rurales y urbanas precarizadas, aisladas y relativamente pequeñas e, incluso, sectores de unidades habitacionales más amplias, y d) Emprendimientos asociativos pequeños o microempresas.

Este conjunto abigarrado de unidades económicas, en su gran mayoría, carecen de estructura de organización formal y de reconocimiento jurídico. Su ideología es imprecisa, difusa y endeble, sin lograr configurar un código de ética definido, por lo que en el desempeño de sus funciones cotidianas pueden llegar a especular, traficar y engañar al público.

El carácter informal que asumen algunas expresiones de la EP responde tanto a la falta de empleo como a las bajas remuneraciones que ofrece la mayoría de las empresas del sector formal. En efecto, la tasa de crecimiento de la economía nacional es insuficiente para generar los empleos que el país necesita y que ascienden a 1,3 millones por año; pero, en 2017, según diversas estimaciones, no se creó ni la mitad de esos empleos, con lo que el desempleo abierto o pasivo acumulado en los últimos años da un total de 11,1 millones de personas, lo que equivale al 18,3\% de la fuerza laboral disponible del país.

Por otra parte, de acuerdo con datos recientemente publicados por el Instituto Nacional de Estadística, Geografía e Informática (INEGI, 2018), se estima que la población ubicada en la economía informal alcanza el $56,8 \%$ de la Población Económicamente Activa (PEA), equivalente a 30,2 millones de personas. La mayor parte de estos trabajadores son jóvenes de entre 14 y 24 años o adultos mayores con más de 64 años de edad, poseen niveles educativos muy bajos y se ubican en cuatro actividades: campo, construcción, servicio doméstico y comercio, percibiendo ingresos menores a dos salarios mínimos, lo que significa que caen dentro de la categoría de pobreza extrema, ya que actualmente para que una familia tenga acceso a una canasta básica de bienes y servicios se requiere de por lo menos cinco salarios mínimos; empero, más del $60 \%$ de quienes tienen un empleo formal recibe diariamente menos de tres salarios mínimos. Por todo ello, no resulta sorprendente que el Consejo Nacional de Evaluación de la Política de Desarrollo Social (CONEVAL) haya calculado que, en 2014, del total de la población mexicana, el 46,2\% se encontraba en estado de pobreza, equivalente a 55,3 millones de personas, de las cuales 11,4 millones se hallaba en pobreza extrema.

El panorama anterior se agrava si se toma en cuenta que la economía informal exhibe una tendencia decreciente en su capacidad de generar valor. Cuantitativamente crece el número de personas en la informalidad, pero su producción es la misma, de forma que sus ingresos disminuyen. Por esta razón, en los Estados en los que la informalidad es mayor, lo es tambien la pobreza. La EP se está convirtiendo en una válvula de escape cada vez más insuficiente para responder a los grandes retos del país, lo que ha provocado el incremento acelerado tanto de la migración como de la violencia organizada, como vías de salida en las que, de forma natural o inercial, caen los que se han quedado sin oportunidades de desarrollo personal y colectivo.

En este contexto macroeconómico altamente desfavorable, lo que esencialmente motiva las acciones de los distintos subsectores de la EP es un interés egoísta e inmediatista y, en menor 
medida, un interés exclusivista o mutualista. Muy pocas de sus acciones tienen un efecto universalista y prácticamente no ejercen el altruismo, ni el solidarismo.

Los criterios de cálculo económico y de organización del trabajo en la EP, se limitan a garantizar la reproducción de la unidad económica de que se trate. Por esta razón, muchas veces solo producen para el autoconsumo y, en menor medida, para el mercado. Sus ingresos se complementan con trabajo asalariado temporal, remesas, donaciones y subsidios gubernamentales.

De esta manera, la falta de articulación, así como el fuerte peso de los intereses individualistas y egoístas o de pequeños grupos, les impide configurar un proyecto general, sectorial o gremial que vaya más allá de la lucha diaria por la sobrevivencia.

En cualquier caso, los participantes en la EP se mantienen unidos a través de solidaridades de tipo tradicional como las que se dan al interior de la familia o las corporaciones, afirmándose mediante el desarrollo de lealtades familiares, de parentesco, o derivadas de la pertenencia a un determinado grupo o clan. Por esta razón, en una posición extrema, pueden llegar a caer en desviaciones como el llamado "familismo amoral", un concepto acuñado por Banfield (1958), para referirse a una situación en la que impera la "lealtad extrema a la familia por sobre cualquier norma social más amplia".

Los pocos emprendimientos asociativos de la EP como la economía campesina de autoconsumo o la producción en el taller artesanal comportan una escasa DST y un alto grado de autonomía en la toma de decisiones respecto a las estrategias empresariales a instrumentar, las cuales habitualmente se circunscriben a una pequeña localidad y raramente tienen un compromiso explícito con el cuidado del medio ambiente.

Su distanciamiento respecto a la intervención estatal es significativo, pues sus actividades económicas no están cubiertas por las políticas públicas de fomento y promoción, razón por la cual no existen arreglos formales de fiscalidad y, consecuentemente, carecen de protección laboral y de prestaciones de desempleo y seguridad social.

Con base en lo hasta aquí señalado, por EP entenderemos al modelo de organización social del trabajo esencialmente autónomo, en el que la inversión de esfuerzo es directamente proporcional a la necesidad de reproducción social de la familia o de la unidad económica, pudiendo calificarse también como el esfuerzo de producir para el uso propio, proveyendo los medios indispensables que aseguren la sobrevivencia de sus miembros.

\section{La Economía Social}

Los actores de la ES son asociaciones y empresas legalmente constituidas, sujetas a la regulación establecida en leyes específicas que les determinan su estructura y funcionamiento, pudiendo adoptar las distintas figuras asociativas señaladas en el artículo 4 de la Ley de Economía Social y Solidaria (LESS), esto es: ejidos, comunidades agrarias, sociedades de solidaridad social, sociedades cooperativas, empresas que pertenezcan mayoritaria o exclusivamente a los trabajadores, y en general, todas las formas de organización social para la producción, distribución y consumo de bienes y servicios socialmente necesarios.

Al contar con personalidad jurídica y convertirse en pagadores de impuestos, pueden funcionar legalmente como sujetos de desarrollo económico y ser destinatarios naturales de las políticas públicas de fomento económico. Sin embargo, la legalidad también las obliga a darse de alta en diversos registros públicos y a someterse a la vigilancia y supervisión de distintas instituciones públicas.

La formación de este tipo de organismos generalmente se produce cuando los individuos se convencen a sí mismos que la obtención de beneficios económicos o la defensa efectiva frente a amenazas o agresiones del entorno, no pueden ser garantizadas como producto de la exclusiva acción individual. Nacen, por tanto, como respuesta a una necesidad real de ámbito grupal o comunitario, que es relevante y significativa en su vida cotidiana y que no ha sido satisfecha.

Pueden surgir también como resultado de la puesta en marcha de políticas públicas destinadas a fomentar la inserción laboral y productiva de sectores excluidos, como parte de los mecanismos corporativos y clientelistas basados en el intercambio de intereses o como resultado de la acción empoderadora de un organismo externo. En cualquiera de estos tres casos, la naciente organización social, para llegar a ser realmente autónoma, tiene que pasar por un complejo y prolongado proceso de consolidación organizacional o morir en el intento.

Pero, independientemente de las vicisitudes inherentes a sus distintos procesos de gestación y maduración, lo cierto es que, de acuerdo con el estudio diagnóstico de la ES realizado en 2013 por el Instituto Nacional de la Economía Social (INAES), había en México 60943 organismos de la ES, de los cuales más de la mitad eran de tipo agrario, entre los que sobresale la existencia de 29 mil ejidos y 2 mil comunidades. Por su parte, las cooperativas alcanzaban la cifra de 13 mil y se estimaba la existencia de cerca de 2 mil Sociedades de Solidaridad Social.

En el medio rural, la importancia económica de la ES se confirma en su potencial productivo, ya que como señala el Compendio de Información Básica 2013-2017 de la Economía Social en México, publicado por el INAES en 2017, los organismos de la ES poseen: "más de 100 millones de hectáreas (51\% del territorio nacional), $80 \%$ de bosques y selvas y $66 \%$ de los litorales del país; a lo anterior hay que agregar que en estos territorios están asentados la mayoría de los 68 grupos etnolingüísticos existentes en nuestro país...".

No existen investigaciones oficiales que den cuenta de la población total agrupada en los distintos organismos de la ES, ni tampoco de su aportación al PIB y a la generación de empleo. Sin embargo, diversos estudiosos del tema calculan tales rubros en 20 millones, 3\% y $14 \%$, respectivamente.

Ahora bien, una vez constituidas, las empresas sociales están legalmente autorizadas para participar en cualquier rama de actividad económica y en todo el ciclo económico que incluye la producción, comercialización y consumo de bienes y servicios.

Su financiamiento se obtiene de recursos propios provenientes del pago de certificados de aportación que confieren la calidad de asociado a las personas físicas, ya sea como trabajadores o como usuarios. Esto significa que no dependen de subsidios ni donativos; aunque, en determinadas circunstancias, se pueden 
emplear a condición de que no comprometan la autonomía de gestión del emprendimiento asociativo.

En su funcionamiento operativo asumen un doble carácter: como empresa y como asociación; pero, bajo el entendido de que la empresa es el medio y no el fin último o exclusivo. Por tanto, son empresas de personas y no de capital, basadas en la propiedad social de los medios de producción y de la empresa misma, que es de propiedad conjunta.

La distribución de beneficios entre los asociados se realiza en base al trabajo aportado por cada uno de ellos, o bien en función del grado o intensidad en la utilización de los servicios o cualquier otra forma de medición de aportes que se establezcan en las bases constitutivas de la organización.

Para atender a sus necesidades y aspiraciones sociales y culturales forman fondos sociales (de reserva, de previsión social, de educación, de solidaridad, etc.) no repartibles. Dichos fondos se constituyen con parte de los excedentes obtenidos en sus actividades económicas.

Por regla general cuentan con un código de ética implícito o explícito. En el caso de las cooperativas, su ideología se funda en la Declaración de Identidad Cooperativa emitida por la Alianza Cooperativa Internacional (ACl) en 1995, y para el resto de las figuras asociativas, además de lo que señale su ley específica, deben sujetarse a lo dispuesto en los artículos 9 y 10 de la LESS, así como en otros principios y valores que ellos mismos se autoimponen. Por esta razón, las organizaciones de la ES suelen ser plurales desde el punto de vista ideológico, ya que en ellas es compatible la coexistencia de socios de diferentes ideologías políticas y religiosas sin que se desnaturalice la finalidad para la que fueron creadas.

Las acciones colectivas de las organizaciones de la ES están inicialmente motivadas por un interés colectivo de impacto inmediato y exclusivista y solo en la medida en que van ganando en solvencia económica, pueden destinar parte de sus excedentes a fines de interés social, imprimiéndole un impacto altruista, solidario o universalista a sus acciones empresariales.

La razón de ser de las organizaciones de la ES es de tipo económico, aunque nada les impide participar en otros ámbitos como el social, cultural o político. Dentro del campo de lo económico no se limitan a atender los retos de la sobrevivencia propia del día a día, sino que asumen pretensiones destinadas a mejorar el nivel de vida de sus socios, ya sea aumentando sus ingresos y/o disminuyendo sus costos, lo cual implica que sean viables y rentables, desde el punto de vista empresarial.

Las empresas sociales si bien están organizadas para funcionar dentro del mercado, cumpliendo con estándares de eficacia y eficiencia empresarial, que las obligan a establecer niveles destacados de DST y de planeación y evaluación de sus actividades, no persiguen fines lucrativos, en cuanto que el logro de la ganancia sea su única y exclusiva motivación, sino que también procuran crear valor social, ambiental o cultural para el bien común. Además, toda su actividad económica está permeada de contenido ético, por lo que no practican la especulación, la intermediación financiera, la publicidad subliminal, la competencia desleal, la elusión de impuestos o la compra de favores de los políticos en turno. Por tanto, lo que las distingue es un compromiso social en integridad, honestidad y transparencia en la elaboración de productos, en la prestación de servicios y en el contenido y forma de la publicidad con la que se dirigen a sus potenciales consumidores.

A título de ejemplo de los efectos sociales de la acción de este tipo de empresas y que muchas veces cobran la forma de bienes intangibles, puede señalarse que algunas organizaciones de la ES desarrollan una fuerte labor educativa y formativa de ciudadanos responsables y comprometidos socialmente mediante la que contribuyen al ejercicio y perfeccionamiento de la democracia participativa. De este modo, su actividad empresarial expresa una combinación de aspiraciones encaminadas a alcanzar propósitos sociales con métodos propios del "mundo de los negocios". Generalmente los beneficios de orden social se proyectan y son más visibles en su entorno inmediato, es decir, en las comunidades en las que se hallan insertas.

Sin embargo, cumplir simultáneamente tanto con fines económicos como sociales y medioambientales demanda una alta dosis de innovación y creatividad, toda vez que la dimensión económica es continúa, se producen y se venden productos y servicios todos los días en un mercado altamente competitivo, lo cual implica riesgos. Lo social, puede ser menos continuo o sujeto a programación, por lo que se acostumbra a dejarlo inscrito como parte de su misión y encargarlo a comisiones especiales.

En su vida interna las empresas de la ES funcionan bajo el principio de entrada y retiro voluntarios. El asociacionismo que revelan sus estructuras de organización es reflejo directo del grado de confianza adquirido por sus socios, lo cual los estimula a dejar a un lado los intereses individuales y egoístas y a mantenerse unidos en torno a un interés general. De esta manera, logran un nivel aceptable de pertenencia reconociéndose a sí mismos como parte de un determinado grupo social, que comparte una identidad colectiva y un destino común.

Sus vínculos interpersonales se construyen con base en el trabajo asociativo practicando la cooperación y la reciprocidad, por lo cual establecen relaciones no salariales e igualitarias entre los socios-trabajadores que son los propietarios de la empresa $y$, por tanto, del producto o servicio que realizan, atendiendo al principio de igual trabajo, igual remuneración. En caso de contratar empleados, lo hacen respetando sus derechos laborales, procurando el trabajo decente y la no explotación de su fuerza de trabajo.

Al interior de las organizaciones de la ES hay igualdad esencial en derechos y obligaciones de los socios e igualdad para las mujeres. Lo anterior trasladado al proceso de toma de decisiones, se expresa en el principio de un socio, un voto, independientemente de sus aportaciones al capital social. Por tanto, el poder de decisión está en las personas no en el capital. De igual modo, el control de la empresa se distribuye entre sus miembros sobre una base democrática, equilibrada y paritaria, a través de órganos colegiados de administración y vigilancia, sujetos a las decisiones adoptadas por la asamblea general como máxima instancia de decisión y poder.

Frente a otros actores sociales se definen como asociaciones autónomas con capacidad para decidir libre y democráticamente las normas para su organización interna, sin intromisiones o influencias externas. Practican también la integración horizontal y vertical a fin de potenciar su capacidad competitiva como productores o bien para la defensa integral de sus intereses gremiales. 
Al haberse sometido a las reglas del mercado y aceptado la reglamentación jurídica establecida, teóricamente las relaciones entre las organizaciones de la ES y el Estado deberían basarse en la cooperación y la responsabilidad compartida. Sin embargo, no siempre sucede así, ya sea por la falta de apoyo estatal efectivo o por la relación instrumental o de dominación que pesa sobre ellas en los marcos del régimen político neo patrimonialista vigente. Lo anterior determina que las relaciones entre el Estado mexicano y la ES se mantengan en un ambiente de tensión permanente.

Sin duda alguna, las prácticas asociativas y empresariales de la ES se ubican en el campo de la experimentación autogestionaria. Aunque también desarrollan prácticas solidarias de actuación proactiva en la resolución de los problemas más ingentes que afectan a las comunidades en las que operan y, normalmente, lo hacen bajo un enfoque de desarrollo comunitario y regional. En el ámbito ecológico, procuran el respeto y cuidado del medio ambiente mediante la implementación de iniciativas de conservación de energía y reciclaje de desechos.

En el terreno político, de forma individual o a través de sus organismos de integración, despliegan una intensa labor de interlocución y de incidencia política tendiente a lograr que se les dispense un trato equivalente al de los sectores público y privado, en igualdad de condiciones y prerrogativas y con el mismo nivel de apoyo en materia de financiamiento y políticas públicas.

De forma análoga, intentan desarrollar una labor de influencia ideológica y cultural. Como parte de esto, se afanan por difundir su ideario ideológico particularmente entre los jóvenes y los líderes de opinión y por promover el respeto y rescate de la cultura y tradiciones ancestrales de los pueblos originales de México.

En síntesis, por ES entendemos al modelo de gestión social del trabajo, de naturaleza asociativa y autogestionaria, constituido por el conjunto de asociaciones y empresas de propiedad social y gestión democrática, que cuentan con personalidad jurídica propia y que han decidido operar dentro de las reglas del mercado sin ánimo de lucro y con una finalidad de justicia distributiva y de protección del medio ambiente.

La economía solidaria

El surgimiento de las iniciativas de ESD responde, no solamente a los imperativos de orden económico que demandan atender las necesidades de reproducción inmediata o de encauzar las legítimas aspiraciones de bienestar de sus socios, sino a otros motivos, aparentemente "no lógicos", derivados del desencanto con el sistema capitalista. Esto último significa que los individuos se incorporan a las organizaciones de la ESD no solo por los beneficios que pueden obtener, sino porque esa participación expresa lo que esas personas son o quieren ser, es decir, sus principios y convicciones acerca del mundo y sus posibilidades de realización humana. Decepcionados del capitalismo, buscan trascenderlo, erigiéndose como una opción política e ideológica para la defensa de la vida, la preservación del equilibrio ecológico y la construcción de una sociedad más fraterna y humanista.
Por tal motivo, los emprendimientos de ESD, poseen una naturaleza integral que les permite participar en todos los planos de la vida social, desde el económico hasta el político y cultural. En el ámbito económico intentan organizar las distintas fases de producción, distribución, intercambio, consumo y postconsumo, de acuerdo con una racionalidad reproductiva de la vida de todos los trabajadores y de la propia naturaleza, convirtiendo la práctica de la solidaridad entre las personas y grupos en un modo de vida y en la forma preferente de atender las necesidades sociales.

Las expresiones de la ESD son heterogéneas pudiendo expresarse a través de prácticas y formas de organización formalizadas o no, de carácter empresarial o comunitario y con figura legal o sin ella. Algunos de sus ejemplos más representativos son: a) sistemas de monedas sociales no convencionales; b) trueque y multitrueque organizados socialmente; c) bancos del tiempo; d) prácticas de trabajo voluntario comunitario y no remunerado como el tequio, la mano vuelta o la guelaguetza; e) economía de autoconsumo y de traspatio; f) circuitos regionales de empresas sociales ecológicamente responsables que realizan actividades de protección, conservación y reproducción de ecosistemas ${ }^{3} ; \mathrm{g}$ ) ecoaldeas; h) empresas dedicadas a la producción de alimentos saludables u orgánicos, cuyos precios finales incluyen los componentes de gastos de producción, ecológicos y sociales; i) organización de ferias y formación de bancos de semillas ${ }^{4}$; j) cooperativas firmemente comprometidas con el cumplimiento cabal de sus principios y valores y con su misión histórica trascendente, particularmente las de productores nacidas de movimientos de lucha obrero-patronal ${ }^{5}$; k) organizaciones consagradas a la vigencia y promoción de los derechos humanos universales económicos, sociales, culturales y ambientales, y l) organizaciones dedicadas al intercambio equitativo y solidario de productos, ya sea en el mercado nacional o internacional, con reglas justas y bajo control directo de los productores.

Las organizaciones de la ESD poseen también un código ético, pero a diferencia del cooperativismo o la ES que, en razón de la Declaración de Identidad Cooperativa emitida por la $\mathrm{ACl}$ o por imperativo de la LESS, responden a una doctrina general o universal, cada experiencia de ESD define el contenido de su ideario ideológico con los principios y valores que mejor correspondan a su realidad y objetivos. Se distinguen, además, por su fuerte inserción local y por establecer altos niveles de DST y, por ende, de planeación, coordinación y evaluación de sus actividades cotidianas.

\footnotetext{
3 Incluye entre otras actividades: recuperación de especies, aumento de la diversidad natural, introducción de energías alternativas, recuperación de ríos, lagos y bosques para el disfrute, acceso y beneficio para todos y no para la apropiación exclusiva de grupos privilegiados.

${ }^{4}$ A últimas fechas, su práctica se ha extendido por todo el territorio nacional, y sirve para impulsar la conservación dinámica de la diversidad vegetal y animal del país. Lo que se hace en las ferias de semillas es registrar las diferentes especies de germoplasma, intercambiarlos entre los productores y lograr la disposición de éstos a sembrarlos en sus parcelas, con lo que se logra un enorme encuentro e intercambio de saberes.

${ }^{5}$ Sin excluir a priori a las cooperativas de consumidores o de ahorro y préstamo, las cooperativas de productores tienen mejores condiciones para traducir a la práctica su ideario ideológico, por lo que constituyen el referente histórico tradicional del cooperativismo mexicano, aunque también es cierto que, en los últimos años, han sufrido un relativo estancamiento cuantitativo e incurrido en desviaciones ideológicas y políticas importantes.
} 
Sus acciones colectivas están motivadas por un interés colectivo, procurando, en cualquier tiempo, imprimir a su labor un efecto de tipo mixto, tanto exclusivista como solidario y universalista. Lo anterior se explica no por razones de altruismo desinteresado o como producto de una lógica de caridad o asistencia social, sino como parte de una estrategia deliberada que busca vincularse a los sectores oprimidos y explotados de la sociedad a fin de provocar el cambio social. Bajo esta óptica, en lo inmediato, no se trataría solo de contribuir a reducir la pobreza, sino poner el acento en superar las desigualdades sociales y económicas y erradicar la opresión política y la injusticia social vinculadas a dicho flagelo.

Por esta misma razón, la ESD asume una finalidad trascendente encaminada a impulsar la transformación profunda de la sociedad capitalista, intentando ubicarse fuera de la lógica acumulativa del capital. Para lograrlo, asume el reto de propiciar diversos procesos de experimentación social y económica en cuyo marco se creen y recreen nuevas relaciones sociales de producción y de convivencia social y política, se perfeccione la organización ciudadana y se desplieguen estrategias de acción colectiva que empujen los cambios cuantitativos y cualitativos requeridos, hasta alcanzar el bienestar espiritual y material de la humanidad en armonía con la naturaleza.

En su vida interna, los organismos de la ESD, en términos generales, desarrollan el mismo tipo de interacciones que las entidades de la ES, pero con énfasis en establecer relaciones de tipo solidario, bajo el entendido de que solo las organizaciones que construyan la solidaridad, como hábito y norma de la interacción social, merecerán tal calificativo.

A nivel externo, son refractarias a la regulación de sus actividades, por lo que renuncian a obtener reconocimiento legal que implique perder autonomía de gestión para desplegar su creatividad en un ambiente de libertad. En materia de política pública solo aceptarían participar en condiciones de co-construcción, es decir, en donde todas las fases de la política pública fueran negociadas entre los representantes de tales organizaciones y los funcionarios públicos.

Con base en lo hasta aquí señalado, resulta evidente que la ESD se distingue por desarrollar prácticas antisistémicas, innovadoras y contraculturales en todas las fases del ciclo económico y en relación con los diferentes aspectos de la vida humana. Se trataría de un conjunto de prácticas en las que la solidaridad es asumida como donación consciente. Así, en el ámbito económico, se conduce por los principios de compartir en lugar de competir, de intercambiar en lugar de dividir, de incluir en lugar de excluir y de colocar en el centro de su actividad al trabajo digno y justo y al reparto equitativo de excedentes entre los asociados, mediante prácticas económicas que no sean subsumidas por la lógica acumulativa y competitiva del mercado capitalista.

Sin embargo, para configurarse como una verdadera alternativa de cambio, las organizaciones de la ESD entienden que no basta con el éxito económico ni con la elevación del nivel de vida de los socios, sino que es fundamental comprometerse con otras finalidades más universales, como la justicia social, la democracia económica, la solidaridad humana, la defensa de la madre tierra, el antibelicismo y la defensa de los derechos humanos universales, un conjunto de demandas indispensables para el buen vivir de todos y todas y que el sistema capitalista no puede resolver.
Además, frente al modelo económico mundial de corte neoliberal que es homogeneizante, dominador y excluyente, la ESD se construye en forma plural y diversificada. Por consiguiente, más que hablar de ESD en singular, debe hacerse referencia a las múltiples y diversas economías solidarias que pueden gestarse y desarrollarse.

En el campo de la ecología, el modelo de ESD propone una gestión de la economía cuya característica distintiva sea el uso racional de los recursos naturales y la protección del medio ambiente. Es decir, una economía que no solo sea eficaz, sino también sostenible desde el punto de vista social y ecológico. Para lograrlo, intentaría retomar la sabiduría y herencia histórica enraizada en las comunidades indígenas, basada en la administración responsable de la naturaleza.

Desde el ámbito de lo político, la ESD, se expresaría por medio de prácticas colectivas de resistencia y emancipación, frente al control político y clientelar de los diferentes grupos de poder. En lo cultural, formaría parte de los esfuerzos de lucha contracultural, motivados y nutridos por una praxis cultural alternativa a la actualmente en boga. Por todo ello y tomando en cuenta que una de sus características intrínsecas es su fuerte compromiso con el desarrollo de un territorio y una población determinada, sus emprendimientos asociativos adoptarían como vía preferente de crecimiento y expansión a la comunitaria y no a la empresarial.

En resumen, el modelo de gestión social del trabajo implícito en la ESD, se caracteriza por su naturaleza asociativa, autogestionaria y solidaria, expresándose como un esfuerzo organizado, deliberado y autónomo de sujetos colectivos para resolver sus necesidades más apremiantes mediante la construcción de un umbral de valores y principios éticos compartidos y el desarrollo paralelo de prácticas alternativas antisistémicas y contraculturales orientadas a la transformación de las relaciones sociales, económicas, políticas, culturales e ideológicas dominantes.

IV. Semejanzas y diferencias entre los tres modelos de gestión

En relación con las semejanzas, es importante advertir que la base material que les da origen y explica su razón de ser, es esencialmente la misma. Esto es: un sistema económico inequitativo e injusto, basado en la explotación y alienación del trabajo humano, así como toda la superestructura política, ideológica y cultural que lo soporta, legitima y reproduce. De igual manera, puede afirmarse que comparten los mismos enemigos. Ciertamente, el enemigo histórico de todas estas formas de organización social del trabajo es el sistema de producción capitalista. Los inmediatos, están representados por todos aquellos agentes que se apropian de una parte considerable del excedente económico generado por dichas unidades económicas, entre los que pueden mencionarse a los usureros, acaparadores, intermediarios, caciques y especuladores de todo tipo que operan a nivel local y regional y, en el plano nacional e internacional: las grandes empresas transnacionales de carácter financiero, productivo y comercial que controlan y manipulan los mercados mundiales en su propio beneficio. 
Asimismo, es posible destacar que el concepto de organización social del trabajo está en la base de las prácticas asociativas y empresariales de la EP, la ES y la ESD, por lo que todas estas formas de economía alternativa y de empoderamiento ciudadano contribuyen a la democratización de la economía, a la dignificación del trabajo y a la justicia distributiva y lo hacen, además, sin fines lucrativos y desde una determinada plataforma ética y un nuevo concepto de progreso y bienestar social, constituyéndose en una fuente de inclusión económica y social y en una escuela de formación cívica y humanística.

Lamentablemente también comparten la falta de integración horizontal y vertical de sus estructuras de organización y la dispersión en sus acciones colectivas, por lo que no han logrado constituir un movimiento social unificado.

Por el lado de las diferencias, encontramos que los actores que dan vida a los tres modelos de gestión analizados no son los mismos. Así, de acuerdo con su naturaleza asociativa, descubrimos que más que por empresas, la EP está constituida por individuos, emprendimientos unipersonales o familiares y por grupos económicos informales que, por regla general, desenvuelven sus actividades al margen del marco regulatorio vigente. Además, su código de ética es elemental y difuso; establecen una escasa DST y se caracterizan por el alto grado de espontaneidad y personalismo en la toma de decisiones.

En cambio, las organizaciones de la ES poseen una doble e inestable naturaleza, funcionando, al mismo tiempo, como empresas y asociaciones de personas. Todos los organismos de la ES poseen una estructura organizativa formal y personalidad jurídica propia; su axiología está definida en un código de ética explícito, y logran establecer altos niveles de DST y de planeación de sus actividades cotidianas.

Finalmente, los organismos de la ESD, aunque también son un hibrido de empresa y asociación, ya sea formal o informal, legal o paralegal, lo realmente importante es que en ellos, debido a la fuerte concientización social de sus integrantes, el carácter de asociación de personas es generalmente el factor determinante, mientras que la empresa aparece como un medio subordinado al cumplimiento de una finalidad trascendente. Adicionalmente cuentan con un código de ética implícito o explícito, una fuerte inserción local o comunitaria y altos niveles de DST y de coordinación de actividades.

En suma, podemos estimar que, en términos de los actores participantes, la EP y la ESD son más plurales y diversificadas, comparativamente con la ES, por lo que tendrían mayores posibilidades de crecimiento y expansión, pues su oferta organizativa estaría dirigida hacia un universo social más amplio, si bien los requisitos de acceso serían más laxos en la EP y mucho más exigentes en la ESD. En cuanto a los modelos organizativos empleados, los de la EP y la ESD son más flexibles y, al mismo tiempo, más libres, en la medida en que no tienen que sujetarse a los lineamientos que les defina algún ordenamiento jurídico. No obstante, las formas de organización de la ES y la ESD son mucho más complejas que las que alcanzan a desarrollar los emprendimientos de la EP. El hecho de contar con un código de ética y una alta DST, permite vislumbrar a los organismos de la ES y la ESD como estructuras semi o plenamente profesionalizadas para el ejercicio de la acción colectiva.
Ahora bien, en cuanto a los intereses que motivan sus acciones, aunque en principio los organismos de los tres modelos responden a un interés de tipo exclusivista e inmediato, la diferencia se ubica en relación con su disposición para ir más allá de ese nivel, imprimiendo un efecto solidario y universalista a sus acciones. Resulta evidente que los organismos de la EP revelan una disposición mínima, los de la ES se colocarían en un punto intermedio y los de la ESD, serían los que manifestarían una disposición máxima.

Los comportamientos arriba indicados son producto del contexto económico, político y social en que cada una de estas formas de organización del trabajo desenvuelve sus actividades cotidianas. Lo anterior cobra relevancia si tomamos en cuenta que el capitalismo con su lógica de reproducción y dominación puede transformar en altamente competitiva y egoísta la diaria lucha por la sobrevivencia económica, así como el esfuerzo mancomunado por la elevación del nivel de vida, procesos que tienen lugar en un ambiente de competencia abierta y que irremediablemente pareciera conducir a que los actores de la EP y la ES se ocupen exclusivamente de lo suyo, dando pie al desarrollo de profundos procesos de diferenciación social al seno de algunas de estas organizaciones. Así, por ejemplo, las empresas de ES consideradas "exitosas", al caer en la lógica competitiva dominante en el capitalismo terminan beneficiando a un reducido y selecto grupo de socios que, al encerrarse en una especie de "burbuja", se vuelven insensibles e insolidarios con el resto de la sociedad. De este modo, su interés particular y exclusivista orientado al logro de una mayor seguridad y protección personal y familiar, aun siendo legítimo, no solo es insuficiente para transformar el capitalismo sino que se contrapone al interés general enarbolado por otros actores sociales. En contraste, los organismos de la ESD no se entienden sin el ejercicio de la solidaridad extendida a los demás, aunque no les reporte un beneficio inmediato, pues lo que se busca, en último término, no es ni la rentabilidad ni la seguridad económica, sino la posibilidad de establecer lazos de comunicación con los otros, a fin de crear una red de solidaridades mutuas que, poco a poco, vayan minando el estilo de vida individualista y competitivo del capitalismo depredador. Por tanto, el umbral de la solidaridad y su práctica consecuente, en este caso, se extiende más allá del interés inmediato y exclusivista.

En cuanto a sus fines, las empresas de la ES nacen casi siempre como organizaciones económicas y solamente el convencimiento de que solas no pueden superar los obstáculos estructurales que les impiden alcanzar sus objetivos, es que deciden involucrarse en procesos de articulación gremial con vistas a potenciar sus esfuerzos individuales y desplegar una actividad de incidencia ante los distintos centros de poder político y económico. En el otro extremo, las iniciativas de EP casi no se articulan entre sí, ni con otro tipo de emprendimientos $y$, por consiguiente, participan muy poco en los procesos de interlocución social y política. Sus acciones político-reivindicativas, cuando las hay, manifiestan un alto componente de espontaneidad y anarquía. En cambio, los organismos de la ESD tienen una naturaleza pluriactiva, es decir, participan activamente en todos los planos de la vida social, desde el económico hasta el político y cultural, y lo hacen en forma relativamente ordenada y planificada.

Dentro del ámbito económico, las iniciativas de la EP se limitan al logro de la sobrevivencia y reproducción del núcleo fami- 
liar o la unidad productiva en cuestión. Por su parte, las empresas de la ES si bien atienden las necesidades inmediatas de sobrevivencia y reproducción, aspiran a mejorar la calidad de vida de sus socios. Finalmente, los emprendimientos de la ESD no solo responden a las necesidades inmediatas y buscan elevar el nivel de vida de sus socios, sino que también pretenden trascender el capitalismo.

Como puede apreciarse, el punto de deslinde entre los fines intrascendentes o trascendentes, que exhiben los organismos de la ES y la ESD, respectivamente, responden básicamente a una valoración distinta respecto a las posibilidades reales de satisfacer las aspiraciones sociales, políticas y culturales de sus agremiados en los marcos del sistema económico vigente. De esta suerte, mientras las empresas de la ES confían en que tales aspiraciones aún se pueden satisfacer dentro del modo de producción capitalista, los emprendimientos de la ESD creen que dicha satisfacción solo se puede alcanzar, a cabalidad y con total plenitud, en un contexto post-capitalista.

En lo que respecta a las interacciones socioeconómicas y culturales establecidas hacia dentro y hacia afuera, encontramos que, en el caso de las unidades colectivas de la EP, las interacciones entre sus integrantes están basadas en solidaridades de tipo tradicional, respaldadas por lealtades familiares o de parentesco. La distribución del ingreso, en un marco generalmente de escasez, se realiza, en un primer momento, atendiendo a las necesidades más urgentes y posteriormente, bajo un criterio de equidad.

Por su parte, las empresas y asociaciones de la ES comparten una identidad colectiva común con altos niveles de confianza y reciprocidad, lo que les permite consensuar una normatividad a la que se someten voluntariamente. Sobre esta base, consiguen practicar la cooperación en el trabajo, la democracia en la toma de decisiones, la equidad en la distribución de excedentes y la solidaridad por alguna razón social. De igual manera, expresan una especial preocupación por cultivar la equidad de género, la atención a las necesidades y aspiraciones intergeneracionales y el cuidado del medio ambiente. Finalmente, cabe destacar, que los organismos de la ESD desarrollan interacciones similares a las entidades de la ES, pero con especial énfasis en las relaciones de tipo solidario.

Respecto a las interacciones hacia fuera, los colectivos de la $E P$, dada la falta de incentivos gubernamentales, prefieren mantenerse al margen de la formalidad y en la semiclandestinidad, desplegando un protagonismo de bajo espectro. En sentido opuesto, las empresas de la ES, al haber aceptado los retos que entraña su reconocimiento legal, buscan relacionarse con diferentes grupos de interés. En el caso de los gubernamentales, lo hacen para beneficiarse de las políticas públicas de fomento económico y, en sus relaciones con los grupos de interés de carácter privado, para establecer alianzas estratégicas que les permitan alcanzar sus metas empresariales. En ambos casos, su política de relaciones está sujeta al principio de no comprometer su autonomía e independencia. En el ámbito de lo estrictamente empresarial, sus relaciones con el exterior están sujetas a los lineamientos de la RSE, esforzándose por establecer un compromiso sólido con las comunidades en las que desarrollan su actividad. Por su parte, los organismos de la ESD comparten con los de la EP el desinterés por la formalidad. No esperan que sus actividades sean reguladas por ningún ente externo, ni aspiran a contar con reconocimiento legal que implique pérdida de libertad de acción, amén de autonomía e independencia. Un recelo similar manifiestan respecto a las políticas públicas.

Finalmente, en relación con las prácticas sociales y empresariales, es interesante advertir que las diferencias entre la EP, la ES y la ESD tienen que ver con la visión estratégica que cada organización se plantea desarrollar a largo plazo y, por ende, con el grado de profundización y radicalización de las prácticas sociales implementadas.

Así, en el caso de la EP, sus prácticas empresariales no tienen un carácter ordenado y sistemático, sino que están determinadas por la espontaneidad del diario acontecer, presentando un alto grado de variabilidad. Por ejemplo, aunque generalmente suelen ajustarse a los requerimientos del mercado, en ciertas ocasiones y bajo determinadas circunstancias, pueden incurrir en prácticas consideradas como ilícitas, tales como el contrabando y la piratería. Por eso, su estrategia de crecimiento a largo plazo se da preferentemente por la vía comunitaria que les resulta más segura o menos riesgosa. A nivel de lo político, si acaso despliegan alguna estrategia, ésta se inscribe dentro de las acciones de resistencia y adaptación. Su debilidad económica y su escasa formación política e ideológica, que, en lo general, no ha superado el nivel de la conciencia en sí, la hace muy susceptible a las presiones y chantajes provenientes del clientelismo y el populismo.

Por lo contrario, en la ES, debido a que sus prácticas se enmarcan en las típicas del mercado capitalista, privilegiando la estrategia de desarrollo empresarial, se exige un alto grado de conducta impersonal, se restringen las lealtades familiares, se individualiza el poder de votación, se acepta la racionalidad jurídica para las sanciones y no priva el paternalismo sino el eficientismo empresarial, lográndose, de este modo, una regulación normativa del comportamiento de sus miembros, que se institucionaliza bajo un sistema de normas, jerarquías y burocracia administrativa. Como puede apreciarse, la carga del componente económico está presente en forma muy fuerte desde el principio y hasta el fin y solamente cuando éste alcanza un cierto nivel de estabilidad, se empieza a desarrollar una labor educativa de los socios, conforme a un plan preconcebido y un presupuesto destinado a dicho fin. Si las actividades formativas se vuelven cotidianas, adquieren un carácter profesionalizado y se inspiran en métodos educativos no convencionales, pueden asumir un contenido contracultural. En materia política, su estrategia de acción colectiva normalmente se encuadra en la resistencia y la adaptación, aunque su doctrina filosófica posee potencial para desplegar estrategias de emancipación.

Por su parte, la ESD se caracteriza por implementar prácticas antisistemicas, innovadoras y contraculturales en todas las manifestaciones de su acción colectiva. Su enraizamiento local constituye una de sus características intrínsecas, por lo cual se inclinan preferentemente por la vía de desarrollo comunitario más que la empresarial. En términos políticos, su estrategia de acción asume un carácter esencialmente emancipatorio y aunque también implementa actividades de resistencia, lo hace con una visión de ruptura sistémica.

Puede concluirse que las entidades de la EP se mantienen como unidades exclusivamente económicas, mientras que las que forman parte de la ES, en su calidad de organismos de base, se comportan también como organizaciones económicas, de- 
legando la actividad político-reivindicativa a sus organismos de integración gremial. Por el contrario, las entidades de la ESD nacen como organizaciones económicas y político-reivindicativas, manteniendo esa doble naturaleza a lo largo de su trayectoria, la cual se potencia cuando se articulan con otros organismos del mismo tipo.

\section{Conclusiones}

Vista en su dinámica cotidiana, la acción colectiva de las expresiones organizadas de la EP, la ES y la ESD, soportada en sus diferentes modelos de gestión del trabajo, se materializa como un continuum que, con grados distintos, actúa sobre las dimensiones económica, social, política, cultural e ideológica, por lo que su impacto real debe valorarse en razón de los resultados concretos. No obstante, de acuerdo con lo expuesto, el trabajo autónomo es capaz de garantizar la sobrevivencia y la reproducción de las entidades económicas que lo practican. El trabajo asociativo-autogestionario reconcilia al trabajador con el producto de su trabajo, eliminando la explotación y la alienación derivada de su apropiación privada y, el trabajo asociativo-autogestionariosolidario, además de lo anterior, perfila la posibilidad de construir otros mundos posibles.

Bajo esta perspectiva y tomando en cuenta las condiciones en que se desenvuelve el capitalismo contemporáneo, el modelo de gestión de la ESD, aparece como el único plenamente revolucionario, dado el carácter antisistémico de sus prácticas asociativas y empresariales, lo que equivale a reconocer que su lógica de funcionamiento difícilmente puede ser subsumida por el capital. Esto último explica la resistencia de los emprendimientos de la ESD a encuadrarse dentro de espacios predefinidos, optando por mantenerse como un movimiento social versátil, discontinuo y siempre cambiante.

La ES expresa, por su parte, una tendencia latente, influida muchas veces por las políticas públicas, las determinaciones del marco jurídico o las presiones de la cultura política a acuerparse y estabilizarse sectorialmente, mientras que la EP aparece simplemente como masa informe e imprecisa, a veces como resabio del pasado y otras como si estuviera en proceso de transición hacia algo distinto e indefinido, siendo objeto de manipulación constante a través de los mecanismos de control clientelar y corporativo. Lo anterior es tan cierto que, hoy en día, las dos características que distinguen a la EP es la informalidad de sus actividades económicas y la pobreza de sus trabajadores, por lo que es absurdo suponer que uno de los dos términos se resolverá sin atender el otro. En nuestra opinión, deberían cancelarse o reducirse al mínimo las políticas asistenciales de combate a la pobreza hasta ahora implementadas sin resultado favorable alguno y poner en marcha una consistente política pública de apoyo a largo plazo de la EP, ofreciendo los incentivos necesarios y la capacitación organizacional indispensable que les permita superar sus actuales debilidades, permitiéndoles optar por mantenerse como economía familiar autosostenible, asumir alguna de las figuras asociativas de la ES, o trasladarse a la ESD.
Y es que, aun cuando en apariencia la EP pareciera ser el modelo de organización social con mayores debilidades y limitantes, debemos reconocer que no solamente se trata del más numeroso y el que presenta mayor tasa de crecimiento anual, sino el que expresa mejor capacidad de resiliencia frente a calamidades de todo tipo, ya sean depresiones económicas, desastres naturales, epidemias, hambrunas, guerras, invasiones de potencias extranjeras o golpes de Estado. En tales circunstancias, cuando todo parece perdido, cuando el propio Estado parece zozobrar, la EP resiste y saca la cara por todos. Esto lo podemos comprobar en numerosos episodios de la historia nacional, pues justamente en los momentos más difíciles, el país salió adelante porque las familias y las comunidades se unieron entre sí, se brindaron apoyo mutuo y solidaridad y lograron, de ese modo, sobrevivir a las peores tempestades.

Por ello, no se trata de decretar un modelo como superior o preferente sobre los otros, sino comprender la utilidad que cada uno de ellos, en cuanto prácticas populares de resistencia ante la dominación del capital, puede dar a la dignificación del trabajo, que es el principio rector de todas estas formas de economía alternativa. Así pues, queda como tarea derivada de las presentes reflexiones, un elemento fundamental que tiene que ver con la necesidad de consensuar una estrategia de acción política incluyente de todos los modelos, que permita incorporar a los actores de la EP, la ES y la ESD dentro de un subsistema económico orgánicamente articulado, que haga las veces de frente anticapitalista y que se oriente a la transformación sistémica, bajo el principio de respetar y alentar la diversidad de formas de hacer economía.

\section{Bibliografía}

BANFIELD, E. (1958): The Moral Basis of a Backward Society. New York, Free Press.

CADENA, F. (2005): De la economía popular a la economía de solidaridad, México, Publicaciones Editoriales Nueva Visión.

CARACCIOLO, M. y FOTI, M. (2003): Economía Solidaria y Capital Social: Contribuciones al Desarrollo Local. Buenos Aires, Paidós.

CONEVAL (2015): Informe de los resultados de la medición de pobreza 2014, México, disponible en: https://www.coneval.org.mx/SalaPrensa/Documents/Comunicado005_medicion_pobreza_2014.pdf (Consulta: 21/05/18).

CORAGGIO, J. L. (2003): Política social y economía del trabajo. Toluca, El Colegio Mexiquense.

FERNÁNDEZ, D. (2013): "La economía solidaria: El acento latinoamericano", en OULHAJ, L. y SAUCEDO, F., Miradas sobre la economía social y solidaria en México, Puebla, Universidad Iberoamericana-CIIESSM, pp. 107-119.

INAES (2013): Diagnóstico del Programa de Fomento a la Economía Social. México, Secretaría de Economía.

INAES (2017): Compendio de Información Básica 2013-2017 de la Economía Social en México, México, Secretaría de Desarrollo Social.

INEGI (2018): Encuesta Nacional de Ocupación y Empleo, México. Disponible en: www.inegi.org.mx/saladeprensa/boletines/2018/enoe_ie/ enoe_ie2018_02.pdf (Consulta: 21/05/18).

Ley de Economía Social y Solidaria (2015), disponible en: http://www.diputados.gob.mx/LeyesBiblio/pdf/LESS_301215.pdf (Consulta: 9/05/18).

TOURAINE, A. (1987): Actores sociales y sistemas politicos en América Lati$n a$, Santiago, PREALC-OIT. 